\title{
Numerical Assessment of Step-Path Failure of Northwest Wall of A154 Pit, Diavik Diamond Mines
}

\author{
A. Karami Golder Associates Ltd, Canada \\ S. Greer Diavik Diamond Mines Inc., Canada \\ R. Beddoes Golder Associates Ltd, Canada
}

\begin{abstract}
The presence of intact rock bridges in the rock mass and their effect on the formation of step-path failure surface in pit slopes have been the subject of research in the last three decades beginning with the work of Jennings (1970). Step-path failure mechanism has been investigated more recently by rock mechanics engineers and consultants using advanced discontinuum numerical techniques. This paper reviews briefly the state of current application of step-path failure in practice and presents the results of one such investigation into the stability assessment of the northwest wall of A154 pit of Diavik Diamond Mine in Northwest Territories, Canada. Results of the numerical assessment are compared with those of limit equilibrium assessment and the importance of such investigations in practice, in particular in deep open pit mines where high stress conditions near the slope toe is present are discussed.
\end{abstract}

\section{Introduction}

The presence of intact rock bridges within the jointed rock mass in high wall rock slopes may significantly contribute to the stability of the slope when compared to the common assumption of a failure surface comprised entirely of joints. Several continuum and discontinuum numerical codes have become available over the last decade including FLAC/FLAC ${ }^{3 \mathrm{D}}$, UDEC/3DEC (Itasca, 2004) and ELFEN (Rockfield, 2005), each offering some capability of analysing failure paths that include some intact rock bridging. They are of particular interest in the stability assessment of deep open pit mine walls where traditional limit equilibrium techniques are constrained by their inability to present a realistic view of rock mass structure and lack of consideration of the state of in situ stresses within the rock mass. While limit equilibrium techniques provide a simple tool to evaluate kinematics of slope failure dominated by existing structures within the pit slope, numerical techniques are better suited to assessing both structurally controlled and stress-induced failure in deep open pit mines. Further, discontinuum numerical methods can be used to assess the formation of potential failure surfaces comprising both the discontinuous existing rock structures and new fractures induced by failure of intact rock bridges (often referred to as step-path failures). The objective of this paper is to describe and critically review the application of current state-of-the-art numerical techniques in the assessment of step-path failure and stability of the NW wall of A154 pit of Diavik Diamond Mine.

\section{Step-path failure development}

Jennings (1970) was among the first to recognise the importance of step-path failure and developed an analytical technique based on limit equilibrium methods to take into account the effect of intact rock bridges on the shear strength of the rock mass and discontinuities. Ristau (1994) used a technique developed by Call and Nicholas (1978, as per Ristau, 1994) to evaluate the formation of step-path failure at three sites in Idaho. This technique was based on characterizing step-path forming joint sets using field data. More recently, many researchers (Stead et al., 2006a; Yan et al., 2007a; Yan et al., 2007b; Liu et al., 2003) and mining engineers and consultants (Moffitt et al., 2007) have addressed the importance of intact rock bridges in the rock mass for slope stability assessments. This is of particular importance in deep open pit mines where high in situ stresses at the toe of the slope could result in progressive failure of intact rock bridges leading to development of a step-path failure surface. This phenomenon is even more significant and more complex when interaction of deep open pits and underground mining is considered. Stead et al. (2006b) discussed the different levels of analysis of pit slope stability in terms of complexity of the problem and the sophistication 
of solution deemed necessary. They argued that continuum and discontinuum numerical methods are appropriate route and may be necessary to assess the step-path failure in the rock slopes where complex translational slope deformations are observed or predicted to take place. Eberhardt et al. (2003 and 2004) used a hybrid finite/discrete element method to model the progressive failure of massive rock masses. They simulated the 1991 Randa rockslide and with which indicated the importance of intact rock (bridge) failure as well as discontinuity degradation in massive high slopes. Stead et al. (2006a), and Yan et al. (2007a, 2007b) discussed the application of traditional scanline mapping along with digital photogrammetry and 3Dlaser scanning techniques for rock structure characterisation and collection and monitoring of field data. They further elaborated on the use of these more advanced and accurate methods of data collections combined with the application of advanced numerical codes to assess pit wall stability. Moffitt et al. (2007) investigated the effect of rock bridges on discontinuity strength by explicitly quantifying rock bridges using discrete fracture networks (DFN), using FracMan (Dershowitz et al., 1998). Information derived from DFN can be used to upgrade the shear strength parameters of ubiquitous joints to simulate the contribution of rock bridges. The percentage adjustment of friction angle and cohesion was determined from the percentage of rock bridges (which may be either truly intact rock or randomly fractured rock mass separating major joints) as determined from the DFN model. Liu et al. (2003) investigated the stability of foundations of Three Gorges dam in China. They found that in the absence of a through-going failure plane in the dam foundation the presence of rock bridges can play a key role in dam stability.

Kemeny (2005) investigated the time dependent degradation of intact rock bridges using a fracture mechanics based model in which the sub-critical crack growth was taken into account. In this method, an intact rock bridge provides cohesion to discontinuities that is a function of mode II fracture toughness, the size of the rock bridge and the size of the adjacent cracks. The cohesion reduces to zero as intact rock bridge is degraded through sub-critical crack growth.

\section{Rock mass structure characterisation}

The development of a step-path failure surface is mainly controlled by the orientation and spatial characteristics of the present major rock structure including major joints sets, shear planes and fault planes. Step-path failure development requires a shallow dipping discontinuous major joint set crossed by a relatively steep discontinuous joint set in the rock mass (Ristau, 1994). The formation of a failure surface is impeded by the presence of intact rock bridges that may exist along shallow-dipping joint sets. A failure surface may be developed either by i) fracturing through the intact rock bridges in shear (Kemeny, 2005) through time dependent degradation of rock bridges or by tensile fracturing of closely spaced coplanar/parallel joints that are separated by a rock bridge, or ii) by by-passing the intact rock bridges if alternative cross joints are present that allow for a stepped failure surface which minimizes the effect of intact rock bridges on the slope stability.

Spacing and continuity of parallel and/or coplanar joint sets are key factors in the formation of step-path failure planes. While joint spacing and continuity (persistence) can be estimated by field mapping and borehole logging data, the quantification of rock bridge percentage in the rock mass is not an easy task since the most probable failure path cannot readily be interpreted during field mapping. Moffitt et al. (2007), recently, used stochastic discrete fracture network analysis to estimate the percentage of rock bridges in the rock mass while others (Ristau, 1994) have used analytical methods and subjective judgements to estimate this parameter. At this time, due to complexity and variability of rock mass structure and the presence of random joints, there is no unique way to quantify the intact rock bridge percentage in the field.

\section{Step-path failure assessment - The case of the NW Wall, A154 Pit, Diavik Diamond Mine}

Diavik Diamond Mines Inc. (DDMI) began open pit mining from A154 pit in 2003. The northwest (NW) wall of the A154 pit is adjacent to a water retention dyke separating Lac De Gras Lake from the pit. As a result, the NW wall is liable to experience high water pressures which may significantly influence the stability of this wall. Rock mass structure within the A154 pit has been delineated through extensive borehole core logging and pit wall mapping. Table 1 shows the major rock structures controlling the stability of the wall. A steep and a shallow to moderate joint set have been found to dominate the predicted 
mechanical response of the rock mass as mining progresses and pit approaches its final depth although they have not been responsible for any instability at this time.

Table 1 Major joint sets - NW Quadrant, A154 Pit

\begin{tabular}{lcc}
\hline NW pit quadrant & Dip & Dip direction \\
\hline Shallow set & $10 \pm 5$ & SE \\
Steep set & $85 \pm 10$ & NW and SE \\
\hline
\end{tabular}

The percentage of rock bridges within the shallow-dipping rock mass fabric was estimated using a DFN model for the NW wall based on a stochastic analysis of a subset of the field mapping and borehole data. Using this approach to generate multiple realizations of the joint structure, it was estimated that there is greater than $5 \%$ rock bridge along the shallow-dipping joint plane within the $\mathrm{NW}$ wall at a $95 \%$ confidence level. Field mapping data and DFN models indicated a continuous steep joint set with no rock bridge in the rock mass. This method is described in more detail in Moffitt et al. (2007).

As expected, the presence of intact rock bridges within a discontinuous system improves the mechanical response of a jointed rock mass. To quantify this effect, the percentage of intact rock bridges determined from the DFN model is used to scale the joint cohesion and friction angle. The scaled joint cohesion and friction angle is estimated by:

Scaled Joint Cohesion $=(\%$ Rock Bridge $) \times c_{\text {rock mass }}+(1-\%$ Rock Bridge $) \times c_{\text {joint }}$

Scaled Joint Friction Angle $=\tan ^{-1}\left[(\%\right.$ Rock Bridge $) \times \tan \left(\phi_{\text {rock mass }}\right)+(1-\%$ Rock Bridge $\left.) \times \tan \left(\phi_{\text {joint }}\right)\right]$

where $c_{\text {rock mass }}$ is the rock mass cohesion, $\varphi_{\text {rock mass }}$ is the rock mass friction angle, $c_{\text {joint }}$ is the joint cohesion and $\varphi_{\text {joint }}$ is the joint friction angle.

It is notable that the scaled joint properties should only be used in applications where the presence of rock bridges is not intended or can not be modelled explicitly, in which case rock mass structure is represented by continuous joint sets with joint mechanical properties that are scaled to account for the presence of intact rock bridges. This is specifically useful in limit equilibrium analysis where anisotropic function is used to define ubiquitous joints which are assumed to be continuous and therefore provide a conservative solution to stability problem.

Mechanical properties of the two joint sets listed in Table 1 are given in Table 2. The base properties as well as the scaled joint properties are included in this table. The base joint shear strength properties are based on residual cohesion and friction angle and therefore are considered to be conservative.

Table 2 Mechanical Properties of rock mass and major joint sets, NW Wall, A154 Pit

\begin{tabular}{lcccc}
\hline & \multicolumn{2}{c}{$\begin{array}{c}\text { Base joint properties } \\
\text { (residual) }\end{array}$} & \multicolumn{2}{c}{ Scaled joint properties } \\
& $\begin{array}{c}\text { Friction angle } \\
(\text { degrees })\end{array}$ & $\begin{array}{c}\text { Cohesion } \\
(\mathrm{kPa})\end{array}$ & $\begin{array}{c}\text { Friction angle } \\
(\text { degrees })\end{array}$ & $\begin{array}{c}\text { Cohesion } \\
(\mathrm{kPa})\end{array}$ \\
\hline Shallow set & 35 & 25 & 37 & 140 \\
Steep set & 35 & 25 & 35 & 25 \\
Granite & 60 & 2300 & - & - \\
\hline
\end{tabular}

Spatial characteristics of the major joint sets were also determined from several extensive surface mapping programs carried out between 2003 and 2005. Table 3 summarizes the spacing and continuity of the two joints sets identified in Table 1. 
Table 3 Spatial characteristics of major joint sets, NW Wall, A154 Pit

\begin{tabular}{lcc}
\hline NW Pit Quadrant & Spacing $(\mathrm{m})$ & Continuity $(\mathrm{m})$ \\
\hline Shallow set & 5 & $20-30$ \\
Steep set & 5 & $20-30$ \\
\hline
\end{tabular}

Both limit equilibrium and numerical discontinuum modelling were used to estimate a factor of safety of the NW wall, incorporating idealizations of the joint sets and rock bridges described above. The strength reduction scheme of Dawson et al. $(1999,2000)$ was used in the discontinuum assessment to determine the factor of safety. According to Duncan (1996), the factor of safety of a slope is defined as the ratio of actual shear strength of the rock mass and discontinuities to the minimum shear strength required to prevent failure or the factor by which rock mass and discontinuity shear strength must be reduced to bring a slope to the verge of failure. This scheme was coded in UDEC, using FISH, Itasca's proprietary programming language for advanced modelling and access to internal capabilities of Itasca codes. In this routine, rock mass and discontinuity strength parameters, $\varphi$ and c, were reduced sequentially by $5 \%$ intervals and stability assessment was carried out until significant movement was predicted by the model indicating slope failure and identifying the factor of safety. For the purpose of this paper, only the stability of the NW wall at the end of the open pit mining (2008) will be discussed.

Groundwater pressure within the pit wall was estimated with a three dimensional finite difference groundwater flow model (McDonald and Harbaugh, 1988), taking into account the effect of dewatering both from the pit and by a system of underground drainage galleries that will be developed towards the end of the pit life. It was found that dewatering due to underground mining has a limited effect on the NW wall due to its proximity to the lake, its relatively great distance from the underground development, and its distance from a fault zone in the NE wall through which much of the pit inflow (dewatering) takes place. Pore pressure data was input into discontinuum and limit equilibrium models in the form of a pressure grid for stability assessments.

\section{Discontinuum analysis}

The discontinuum stability assessment of the NW wall of A154 pit was carried out using UDEC (Itasca, 2004). NW wall model geometry was built based on major joint sets orientations as identified in Table 1. Sensitivity of the model results were evaluated by scaling the spacing and continuity of joints in the model as opposed to the actual measured spacing and continuity of joints sets while the aspect ratio of blocks were maintained. In addition, joint spacing and continuity was also varied by one standard deviation to account for their variability as indicated by field investigations. Joint orientation was also varied by one standard deviation to account for their variability as identified in the field mapping. Table 4 tabulates the scaled spatial characteristics of the joint sets as modelled in UDEC in comparison with the actual measured spacing and continuity as reported in Table 3. Residual material properties were used in initial UDEC analyses as summarized in Table 2.

Table 4 Scaled spatial characteristics of joint sets in UDEC

\begin{tabular}{lccc}
\hline $\begin{array}{l}\text { NW pit } \\
\text { quadrant }\end{array}$ & $\begin{array}{c}\text { Spacing (SD) } \\
(\mathrm{m})\end{array}$ & $\begin{array}{c}\text { Continuity (SD) } \\
(\mathrm{m})\end{array}$ & $\begin{array}{c}\text { Rock bridge (SD) } \\
(\mathrm{m})\end{array}$ \\
\hline Shallow set & $15(5)$ & $80(30)$ & $15(5)$ \\
Steep set & $15(5)$ & $80(30)$ & $15(5)$ \\
\hline
\end{tabular}

Two UDEC models were setup to carry out the stability assessment and sensitivity analyses. The two models were:

- Base Geometry Case: Based on scaled joint spacing and continuity including variability of joint orientation, spacing and continuity by one standard deviation. The parameter variability was determined from field mapping data analysis. 
- Refined Geometry Case: Based on actual joint spacing, continuity and orientation determined from field data. No variability of joint geometrical parameters was considered in this case due to numerical instability which occurs when a large number of small rock blocks with acute corners are present in the model.

The results of both analyses are presented in the next section.

\subsection{UDEC model based on scaled spatial characteristics of discontinuities - base geometry case}

Figure 1 shows the model geometry and horizontal displacement in the NW pit wall at the end of pit mining in 2008, indicating instability at the toe of the slope. Investigations indicated that high groundwater pressure is the main cause of instability and it was later addressed through studies of actual pore pressure dissipation during mining and active slope drainage. The failure is predicted to occur along shallow dipping joints set daylighting at the toe of the pit. High shear $\left(\sigma_{1}-\sigma_{3}\right)$ stresses are also predicted at the end of pit mining and at the early stages of underground mining near the pit toe, however, further investigations indicated that as underground mining continues these stresses are relieved as they are shed to the competent granite surrounding the root of the mined-out pipe.

The movement along the steep joint set is found to be by separation rather than shear. Figure 2 shows the state of plasticity in the pit wall. Results indicate that the failure surface follows the existing joints sets where present and that tensile failure of intact rock bridges may occur where steep joints are not present as shown in Figure 2. It is notable that since UDEC does not simulate fracturing when tensile strength of rock blocks has been exceeded, it gives the model an artificial constraint preventing it from further displacement.

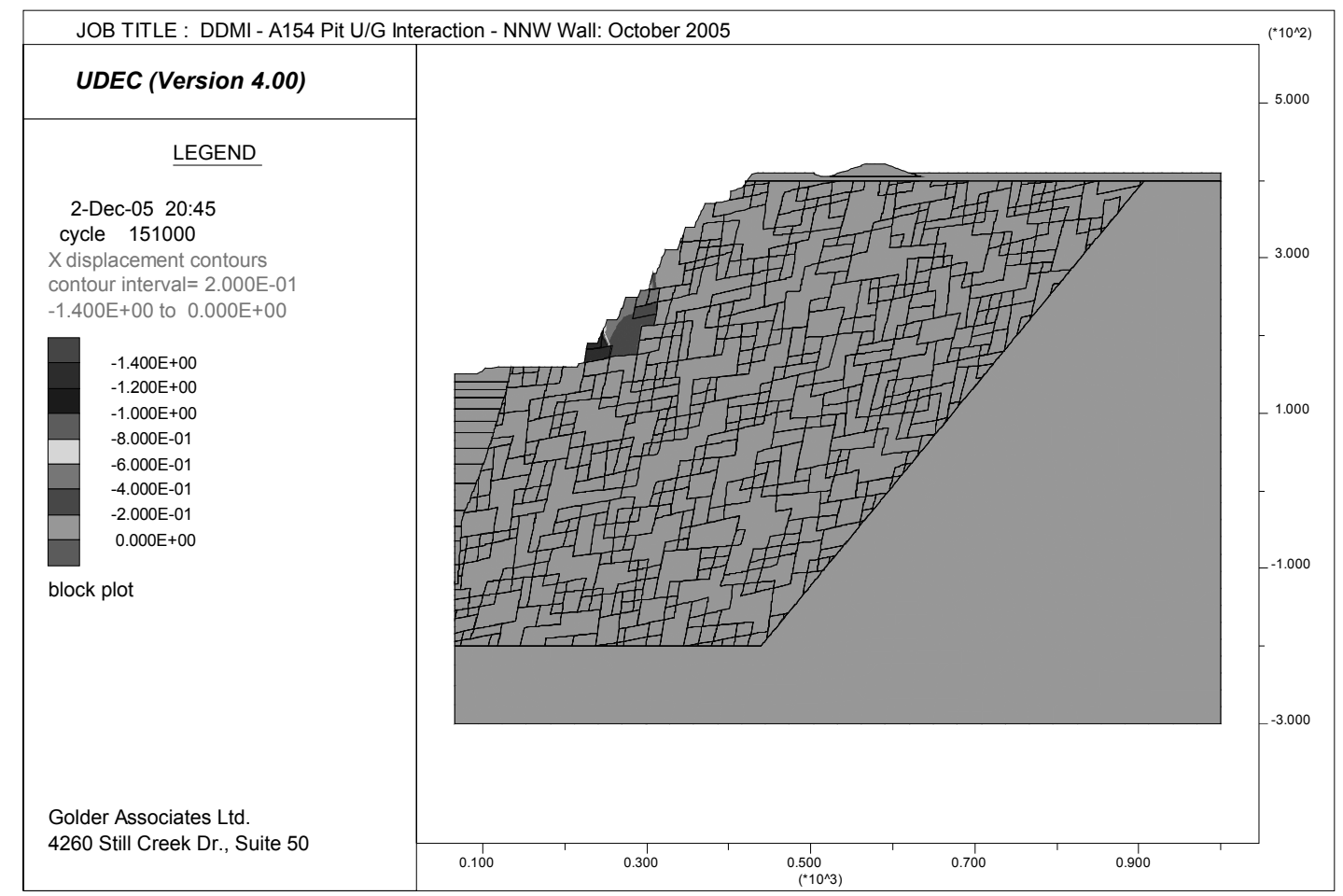

Figure 1 Base model geometry and horizontal displacement contours along the NW wall of A154 pit, joints based on scaled spacing, rock bridge length and continuity 


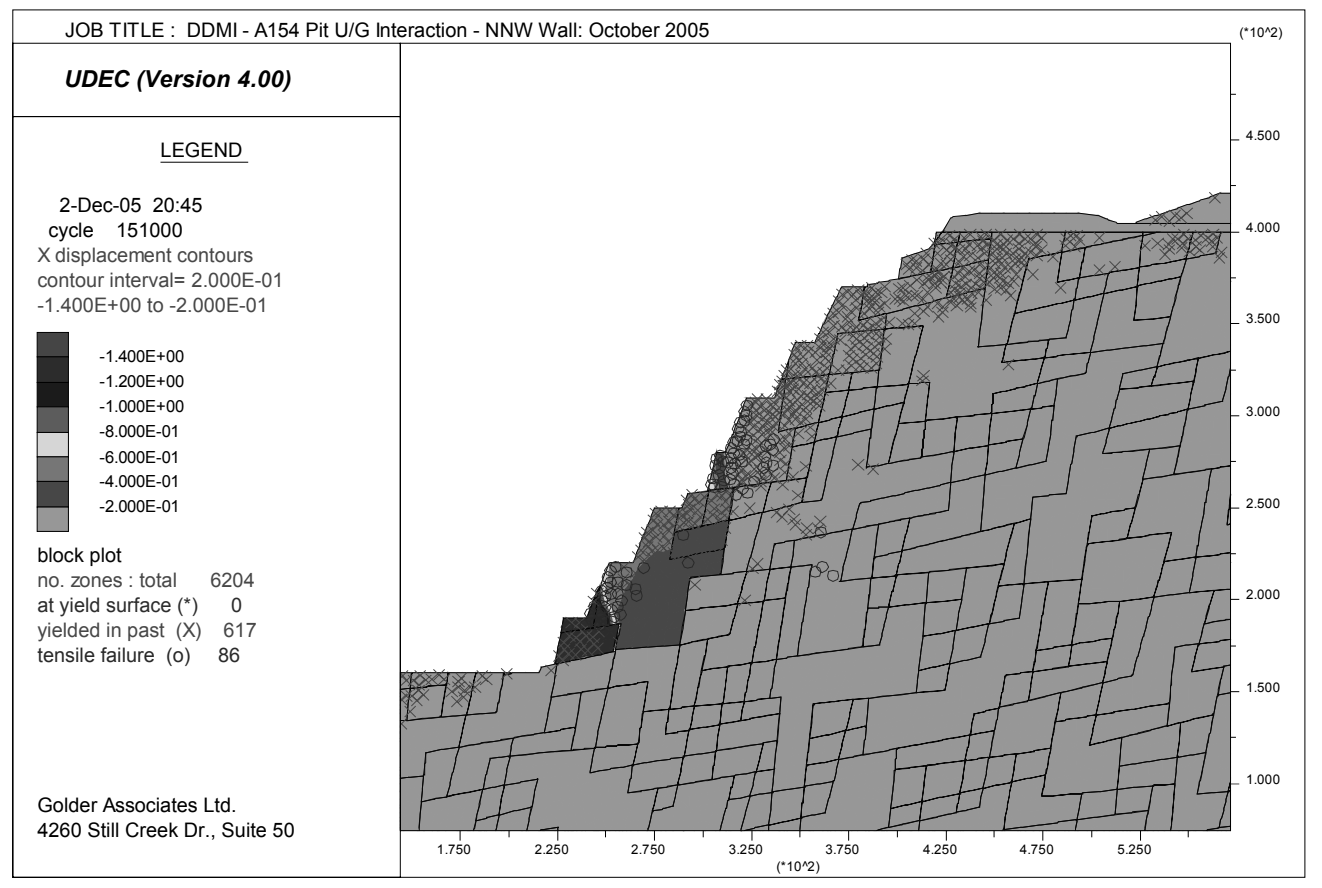

Figure 2 Horizontal displacement contours and state of plasticity along the NW wall of A154 pit; pit slope in state of failure, tensile failure indicate the progress of failure towards the pit crest; joints based on scaled spacing, continuity and rock bridge length

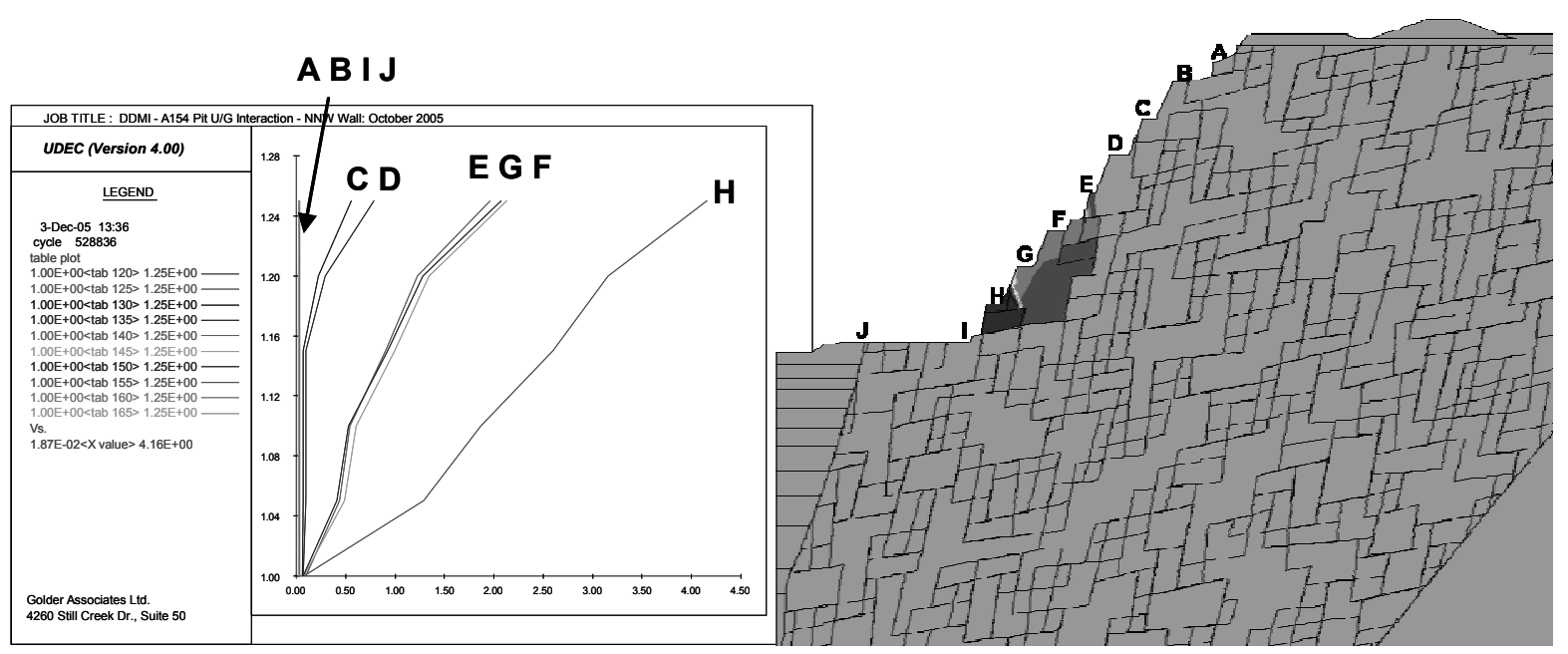

Figure 3 Horizontal displacement profile of monitoring locations at several locations in the pit surface; plot indicates the state of instability at the lower part of the pit neat the toe; displacements increasing towards the pit crest

Figure 3 shows the state of displacement at several locations along the NW pit wall as factor of safety simulation was carried out. As shown, movement near the toe of the pit (monitoring point $\mathrm{H}$ ) constantly increases from the beginning. As the strength reduction scheme is continued movement progresses upward towards the pit crest as indicated by the increasing displacements at the monitoring locations (E, F and $\mathrm{G})$ in the mid height of the pit slope. 
Factor of safety of the NW wall, for this case, was found to be 1.0. Further assessment of material properties used in these analyses indicated that the factor of safety obtained from UDEC was very conservative. These included:

- Rock mass properties were derived from an assessment of rock mass quality and intact rock properties obtained from extensive laboratory testing programs. In addition, a geotechnical block model developed for the A154 pit indicated the rock mass in the northwest wall is comprised mainly of granite with a median $\left(50^{\text {th }}\right.$ percentile $)$ RMR of 75.

- DFN models indicated a minimum rock bridge percentage of $15 \%$ and a median $\left(50^{\text {th }}\right.$ percentile $)$ of $30 \%$, however, a low rock bridge percentage of $5 \%$ (95\% confidence interval) was considered for the design and stability purposes.

- Joint residual shear strength properties were considered in the stability assessments. A friction angle of $35^{\circ}$ and a cohesion of $25 \mathrm{kPa}$ were therefore considered. Peak friction angle of the joints were found to be $55^{\circ}$ with no cohesion. The joint roughness and waviness observed in joints in the field further provides some effective cohesion and supports higher values of peak friction angle.

In addition, further sensitivity analyses were then carried out to obtain better understanding of rock mass mechanical response. The sensitivity analyses included UDEC numerical modelling and SLIDE ${ }^{\mathrm{TM}}$ (Rocscience, 2005) limit equilibrium methods.

Stability assessments also indicated high groundwater pressures are mainly the cause of instability of the NW wall and for an effective stability assessment the groundwater pressure issue must be addressed. As a remediation measure, the effects of dewatering by sub-horizontal or vertical wells on the slope stability were also evaluated and slope factor of safety was determined.

Overall, when limit equilibrium and numerical analyses were repeated considering more realistic joint shear strength properties, rock bridge percentage and artificial dewatering in the pit, the factor of safety of the slope was improved significantly and increased to 1.5 .

\subsection{UDEC model based on actual spatial characteristics of discontinuities - refined geometry case}

To investigate the possible effect on predicted stability of up-scaling the joint geometry, the UDEC model was re-built using the actual joint geometries as given in Table 1 and Table 2. In theory, smaller blocks with randomly located rock bridges within the model better represent the rock mass structure. Figure 4 shows the model of the refined NW wall geometry. In practice, when modelling closely spaced discontinuous joints in UDEC, it is not practical to employ random orientations as was the case with the up-scaled model due to possible formation of acute angles in between blocks. The result of this restriction is that the distribution of intact rock blocks (rock bridges) becomes highly regular throughout the model. Furthermore, due to the density of the jointing and size of the blocks, the model will be large and slow to converge. The presence of small scale blocks and rock bridges nevertheless may provide a better representation of step-path failure surface development.

Figure 5 shows the horizontal displacement across the refined NW wall during factor of safety calculations at $86 \%$ original joint and rock mass strength properties and indicates significant movement as deep as $40 \mathrm{~m}$ from the pit surface. Slope movement, as in the up-scaled case, occurs along the shallow dipping joint sets day-lighting at the toe of the pit. Small scale blocks and closely spaced joints in this model allow the formation of a large scale step-path failure surface along the shallow joint set in contrast to the up-scaled model where development of a step-path failure surface limited by the rock bridges. The factor of safety increased slightly, to 1.05 , indicating that the up-scaled model was slightly conservative but that the overall conclusion regarding the need to investigate the depressurization response of the wall remained valid.

Figure 6 shows the state of plasticity within the NW wall indicating significant tensile failure (fracturing) in the mid to upper part of the pit and significant movement at the toe of the slope. Reduced vertical stresses due to mining and high horizontal to vertical stress ratio also contribute to development of high differential principal stresses (shear stresses) near the slope toe that further contributes to potential instability in this region. Figure 6 shows that there is limited movement along the steep sets; blocks simply separate from the 
adjacent blocks once movement along the shallow joints begins. The presence of yielded zone (in tension) indicates that block movement may progress upward towards the pit crest.

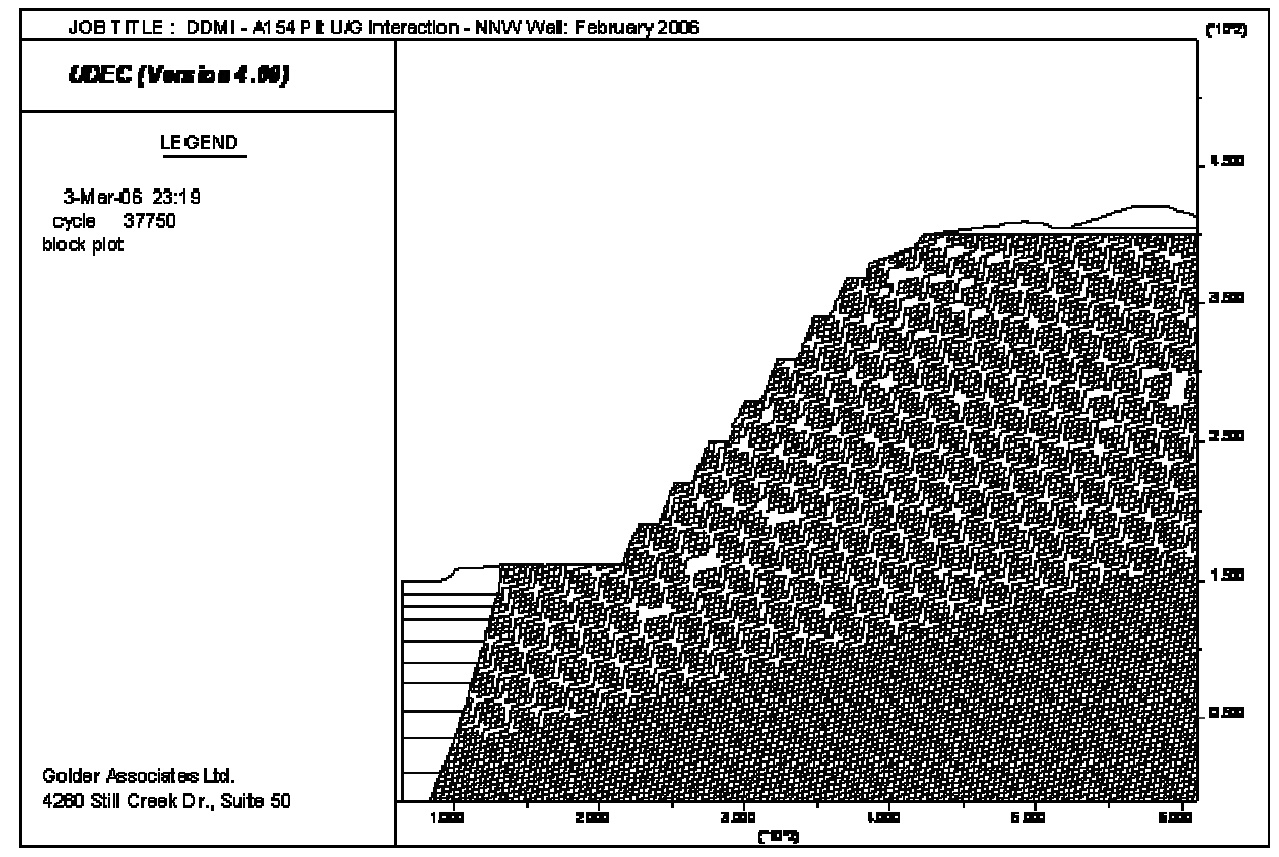

Figure 4 Geometry of NW wall of A154 pit in UDEC, using actual joint spacing, continuity and rock bridge length

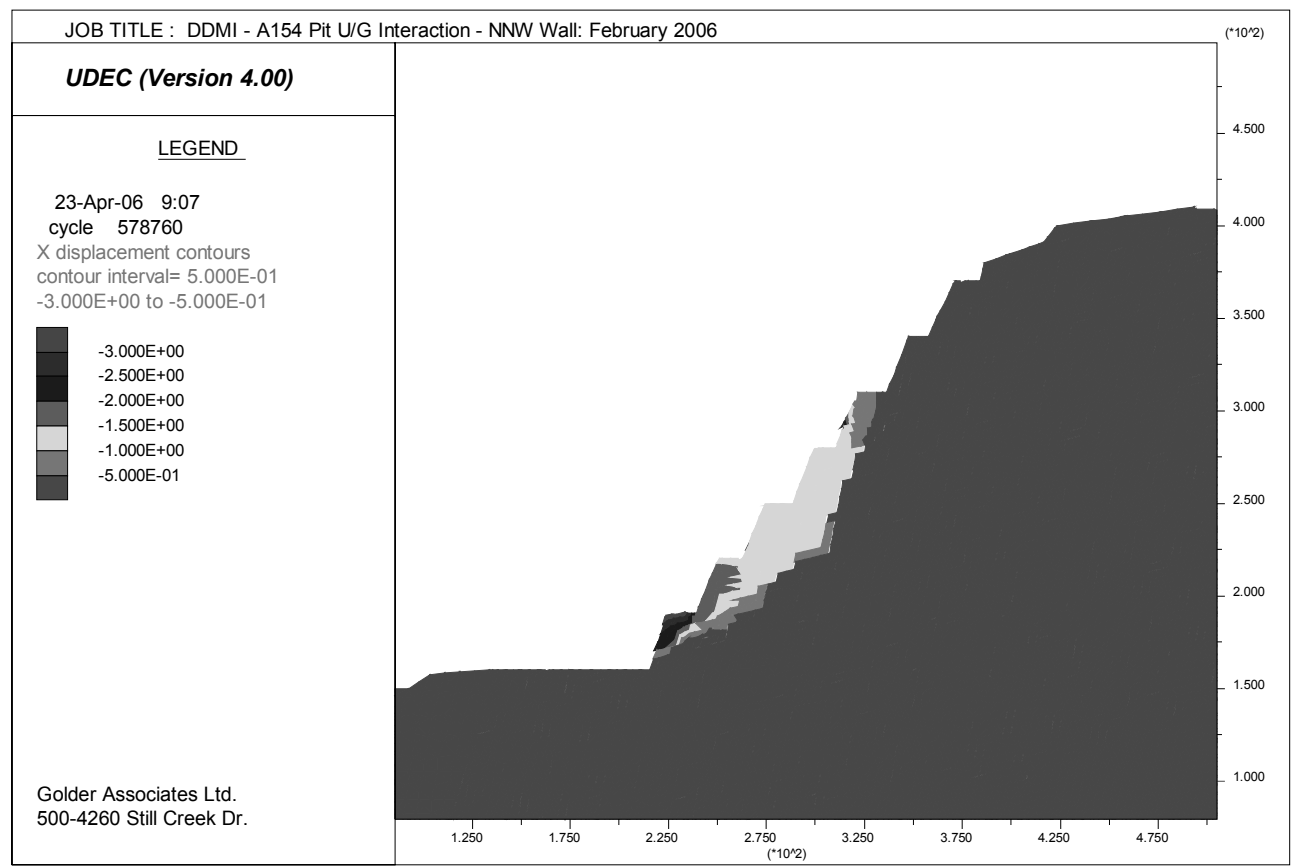

Figure 5 Horizontal displacement contours along the NW wall of A154 pit during factor of safety calculations at $86 \%$ original joint and rock mass strength properties, pit slope in state of failure; joints based on actual spacing, rock bridge length and continuity 


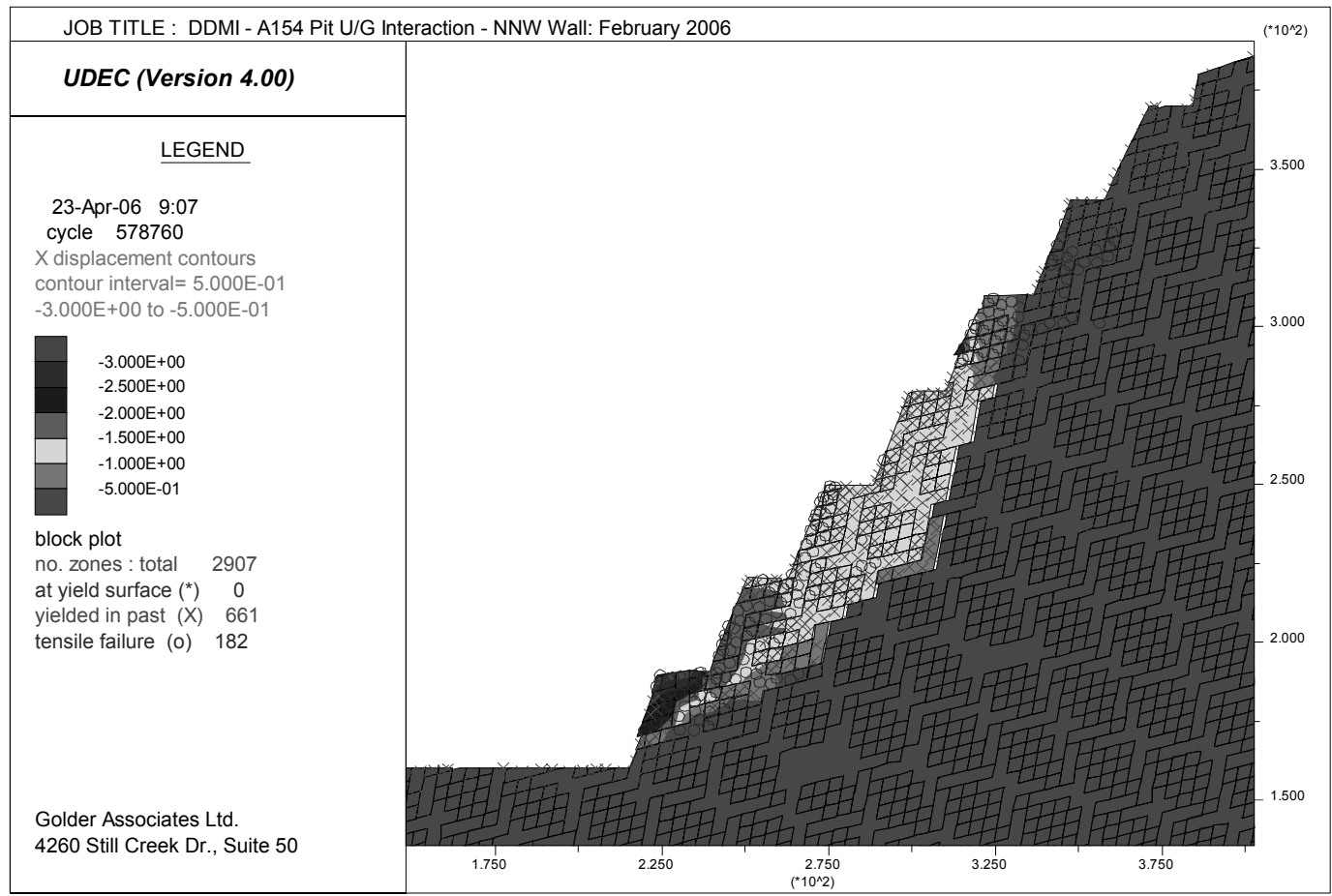

Figure 6 Horizontal displacement contours and state of plasticity along the NW wall of A154 pit during factor of safety calculations at $86 \%$ original joint and rock mass strength properties; pit slope in state of failure, tensile failure indicate the progress of failure towards the crest; joints based on actual spacing, rock bridge length and continuity

Similar to Figure 3, Figure 7 shows the state of displacement at several monitoring locations along the NW pit wall as factor of safety simulation was carried out. For ease of comparison the monitoring locations along the pit surface remained the same as in the base (scaled) joint geometry case (Section 5.1). As indicated by the monitoring point $\mathrm{H}$ in Figure 7, the movement near the toe of the slope begins after rock mass and joint shear strengths (cohesion and friction angles) are reduced by 5\%. As the strength reduction scheme is continued the movement at slope toe increases at an increasing rate indicating slope instability. The movement progresses upward towards the pit crest. This is shown by the increasing displacements at the monitoring locations, D, E, F and G, in the upper parts of the slope as well as the tensile failure of the rock mass in between monitoring points $\mathrm{E}$ to $\mathrm{C}$. The factor of safety for the slope remains unchanged from the base (scaled) geometry model.

A comparison of UDEC results for base (scaled) geometry model versus refined geometry model indicates that refinement of joint geometry while helps develop a more realistic rock mass structure and stability assessment, it does not necessarily represent the rock bridge influence better than scaled model. The fact that UDEC can not model fracture formation through rock bridges plays a key role in this behaviour. In addition, UDEC does not allow open-ended joints; joints not terminating in another joint. The latter leads to another limitation in UDEC in that the rock bridge length in any joint set is limited to a minimum that is the spacing of the cross-joint that must be present to allow formation of a blocky rock mass.

It should also be noted that the effectiveness of intact rock bridges in preventing the formation of a failure surface is strongly dependent on the lack of presence of an alternative step-path along the existing joints so that failure surface can only be formed by breaking through the intact rock bridges. If an alternative step-path is present along the existing joints, the intact rock bridges do not influence the joint shear strength in proportion to the size of intact rock. While this may be true in some cases, in case of UDEC, it is merely an artifact of UDEC modelling as shown in the case of NW wall stability assessment reported in this paper. Such effect would therefore result in a conservative stability assessment. Furthermore, it can be concluded that UDEC can not effectively model the effect of rock bridges. The formation of step-path along the shallow 
joints and through by-passing the rock bridges as shown in Figure 6 confirms this behaviour. As a result, other ways of simulating the influence of rock bridges, such as adding additional cohesion to the joints, must be sought.

\section{Limit equilibrium analysis}

The limit equilibrium analysis was carried out using SLIDE (Rocscience, 2005). The NW wall geometry identical to the UDEC model was built and groundwater pressure was imported from UDEC to ensure both models have identical hydro-mechanical conditions. As stated earlier, core logging and surface mapping data have indicated that slope stability is mainly controlled by rock structure and movement along discontinuities. To account for rock mass structure, the limit equilibrium analysis was carried out using non-circular failure surfaces with potential slip surfaces formed as per major structure orientations as reported in Table 1. The anisotropic strength function was used in SLIDE ${ }^{\mathrm{TM}}$ (Rocscience, 2005) to take into account the weakness planes defined by the ubiquitous joint sets. Using this function, the anisotropic discontinuity shear strength can be incorporated in the stability assessment and the factor of safety of the slope can be found along the weak discontinuity surfaces.

The presence of ubiquitous joints in the SLIDE ${ }^{\mathrm{TM}}$ (Rocscience, 2005) implies that there are continuous joints with no intact rock bridges present in the rock mass. As discussed earlier, to account for the effect of rock bridges in limit equilibrium analysis the scaled joint shear strength properties as reported in Table 2 were used in SLIDE ${ }^{\text {TM }}$ (Rocscience, 2005).

The limit equilibrium method identified that factor of safety of the NW wall is 1.5 against a potential deepseated bi-planar failure surface (Note that since the failure surface is deeper than that predicted as the initial instability by UDEC, the factor of safety differs). Figure 8 shows the limit equilibrium failure surface and the associated factor of safety of the NW wall when scaled joint properties were used. An earlier assessment with limit equilibrium method indicated a factor of safety of 1.35 when residual joint shear strength properties were used. It is notable that the each point in the cloud of points shown in Figure 8 identifies a potential bi-planar failure surface for which a factor of safety is calculated by SLIDE ${ }^{\text {TM }}$ (Rocscience, 2005). The failure surface shown is the one with minimum factor of safety.

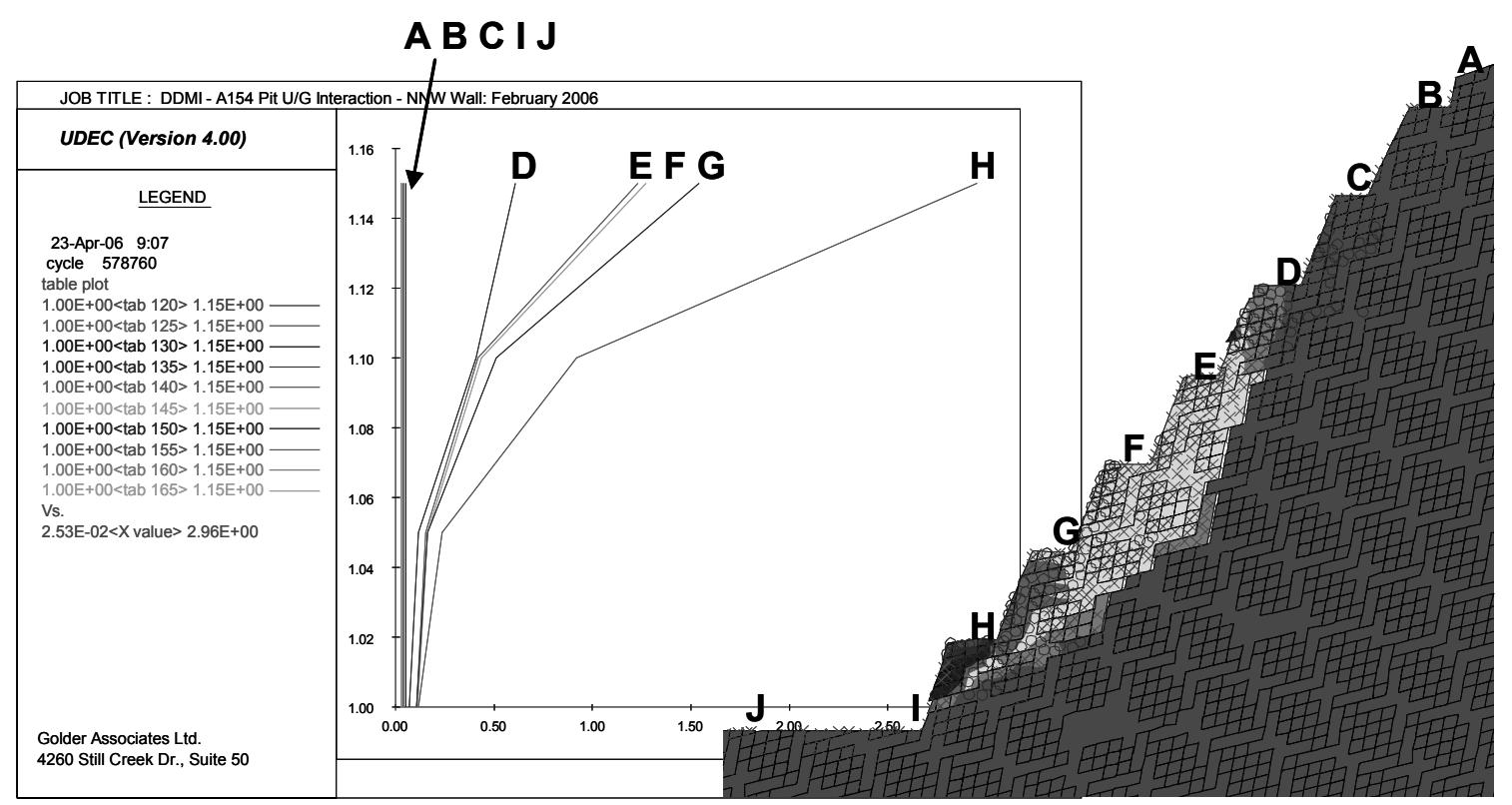

Figure 7 Horizontal displacement profile of monitoring points at several locations in the pit surface; plot indicates the state of instability at the lower part of the pit; displacements increasing towards the pit crest; joints based on actual spacing, rock bridge length and continuity 


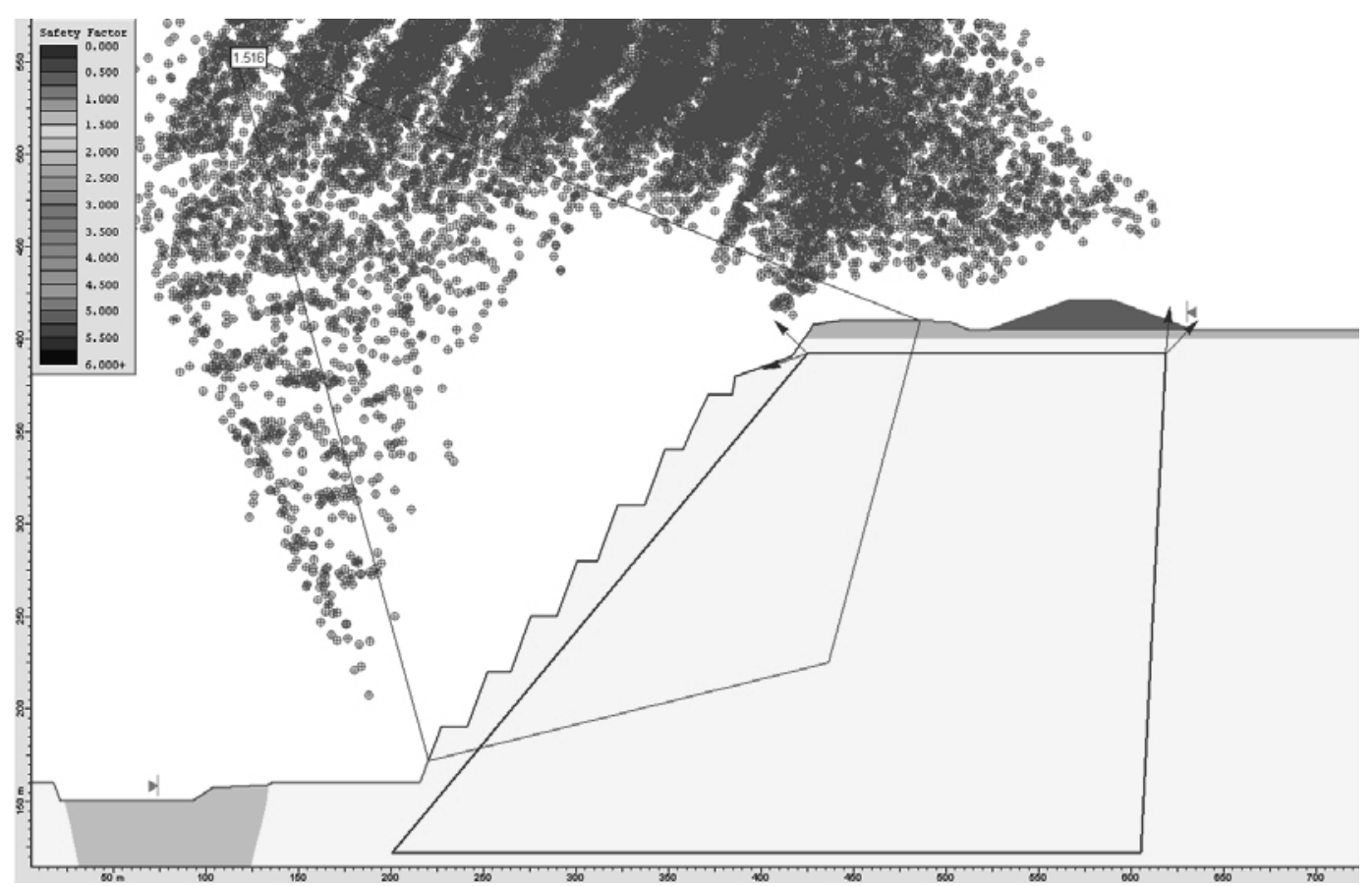

\section{Figure 8 Predicted failure surface along weakness planes assuming no rock bridges present (through-going joints)}

Limit equilibrium analyses indicated that scaling material properties can indirectly, yet effectively, evaluate the effect of intact rock bridges in the rock mass. It however, lacks the ability to examine the in situ stress effect which may play a key role in slope stability when horizontal to vertical stress ratio is large.

\section{Conclusions}

Intact rock bridge failure and step-path formation is an important mechanism that may control the stability of pit walls in deep open pit mines and therefore need to be taken into consideration in pit slope stability assessments. The intact rock bridge failure mechanism is directly related to the state of in situ stresses (shear stresses in case of coplanar joints and tensile stresses in case of parallel joints) mainly at the basal plane of the potential failure surface. Upon failure, rock bridges form a new surface connecting the discontinuous joints leading to the formation of step-path in the rock mass. While this is plausible, it is also important to note that step-path failure surface can also be formed if alternative closely spaced coplanar joints are present in the rock mass in which case the failure surface will form along the existing joints rather than fracturing through the intact rock bridges.

Upon detailed examination of the UDEC analyses the following conclusions can be made:

- Scaling joint geometries in UDEC while maintaining block aspect ratio speeds up the model generation process and reduces the model run time without affecting factor of safety, however, at the expense of coarser less precise step-path failure surface development. The comparison of two scenarios considered for the NW wall stability discussed in this paper confirms this behaviour.

- UDEC has several limitations in simulating intact rock bridges effectively including i) inability to simulate fracturing; ii) disallowing open ended joints; and iii) minimum rock bridge length is limited by the spacing of the cross-joints.

- Discretization routine in UDEC can model step-path formation by slipping along coplanar joints while by-passing intact rock bridges.

- Consequently, UDEC appear to lack the ability to model intact rock bridge failure effectively. 
It is notable that the application of Voronoi Tesselation joint generation scheme in UDEC to simulate rock bridge formation has not yet been investigated thoroughly. Preliminary assessments with this scheme, however, indicate a very slow and numerically expensive solution to rock bridge failure assessments.

Detailed investigation of SLIDE ${ }^{\text {TM }}$ (Rocscience, 2005) analyses also carried out. The following conclusions can also be made with regard to these analyses:

- $\quad$ SLIDE ${ }^{\mathrm{TM}}$ (Rocscience, 2005) can not directly simulate intact rock bridge failure and step-path formation; it however, can simulate weakness planes successfully using ubiquitous joints and anisotropic joint strength function by artificially increasing joint shear properties proportionate to the observed length of the intact rock.

- $\quad$ SLIDE ${ }^{\mathrm{TM}}$ (Rocscience, 2005) simulations are easy to setup and numerically fast and therefore many stability assessments can be carried out in a short period of time.

An alternative way to simulate rock bridge failure that was discussed in this paper is to simulate the effect of rock bridges by scaling joint shear strength properties proportionate to the percentage of the rock bridge length to joint continuity. The additional joint strength would be based on percentage of rock bridges having properties of rock mass. This however, can be carried out in both UDEC and SLIDE analyses.

Further sensitivity analyses can be carried out to investigate the changes in the factor of safety to variations of joint properties which again can be carried out in both analysis techniques.

Limit equilibrium while is not fundamentally robust comparing to UDEC, it can provide a quick solution with reasonable reliability and accuracy. On the contrary, UDEC simulations are not as easy and fast to build and carry out.

If used to simulate rock masses having continuous joints (no rock bridge simulation), UDEC can represent the rock mass more realistically and evaluate the in situ stress effects as well. In such case, similar to SLIDE $^{\text {TM }}$ (Rocscience, 2005), scaled joint material properties shall be used to account for the presence of rock bridges.

Overall, considering UDEC limitations, sensitivity analyses of joint shear strength properties offer a reliable but indirect method of assessing step-path failure. It is to be noted that in such case, a fine mesh based on actual joint spatial geometries better represents the rock mass and to avoid double counting the effect of rock bridges, no rock bridges should be modelled in UDEC. Furthermore, it can be added that UDEC predicts a more realistic failure surface than SLIDE. It therefore can be concluded that to perform a detailed slope stability assessment both models shall be used to provide a complete picture of the in-situ stresses in the rock mass as well as to assess the kinematics of slope instability. Variations of groundwater conditions can also be examined equally in both techniques

\section{References}

Call, R.D. and Nicholas, D.E. (1978) Prediction of step path failure Geometry for slope stability analysis. Proc. 19th US Symposium Rock Mechanics.

Dawson, E.M., Motamed, F., Nesarajah, S. and Roth, W.H. (2000) Geotechnical stability analysis by strength reduction. ASCE Geotechnical Special Publication, Vol. 101, pp. 99-113.

Dawson, E.M., Roth, W.H., Drescher, A. (1999) Slope stability analysis by strength reduction. Geotechnique, Vol. 49, No. 6, pp. 835-840.

Dershowitz, W., Lee, G., Geier, J. and La Pointe, P.R. (1998) FracMan: Interactive discrete feature data analysis, geometric modeling and exploration simulation, User Documentation. Golder Associates Inc. Seattle. Washington.

Duncan, J.M. (1996) State of the art: limit equilibrium and finite-element analysis of slopes. Journal of Geotechnical Engineering, Vol. 122, No. 7, pp. 577-596.

Eberhardt, E., Stead, D., Coggan, J.S. and Willenberg, H. (2003) Hybrid finite-/discrete-element modeling of progressive failure in massive rock slopes. ISRM 2003 - Technology roadmap for rock mechanics, South African Institute of Mining and Metallurgy, pp. 275-280.

Eberhardt, E., Stead, D., Karami, A. and Coggan, J.S. (2004) Numerical Analysis of brittle fracture propagation and step-path failure in massive rock slopes. Annual Canadian Geotech Conf. Quebec City. 8 p.

Itasca Ltd (2004) FLAC/FLAC3D, UDEC/3DEC User Manuals, Itasca Consulting Ltd. 
Jennings, J.E. (1970) A mathematical theory for the calculation of the stability of slopes in open cast mines. Proceedings Planning of Open Pit Mines, Johannesburg, pp. 87-102.

Kemeny, J. (2005) Time-dependent drift degradation due to the progressive failure of rock bridges along discontinuities. International Journal of Rock Mechanics \& Mining Sciences, 42, pp. 35-46.

Liu, J., Feng, X.T., Ding, X.L., Zhang, J. and Yue, D.M. (2003) Stability assessment of the Three-Gorges Dam foundation, China, using physical and numerical modelling - Part I: physical model tests. International Journal of Rock Mechanics \& Mining Sciences, 40, pp. 609-631.

McDonald, M.G. and Harbaugh, A.W. (1988) A modular three-dimensional finite difference groundwater flow model. Techniques of Water-Resources Investigations, 06-A1, U.S. Geological Survey, 528 p.

Moffitt, K., Rogers, S. and Greer, S. (2007) Improved assessment of pit slope stability through the use of realistic fracture network modelling and numerical simulation at the Diavik Diamond Mine. 1st Canada - US Rock Mechanics Conference, May 27-June 1, 2007, Vancouver.

Ristau, J.M. (1994) Field verification of a step-path simulation model for rock slope stability analysis, Master's thesis, University of Idaho, Moscow, ID.

Rockfield Software (2005) Rockfield Ltd., Swansea, UK.

Rocscience (2005) Rocscience Inc., Ontario, Canada.

Stead, D., Yan, M., Elmo, D. and Coggan, J. (2006a) New developments in rock slope engineering: Implications for open pit slope design Sea To Sky Geotechnique 2006, 59th Canadian Geotechnical Conference, October 1-4, 2006, pp. 1054-1061.

Stead, D., Eberhardt, E. and Coggan, J.S. (2006b) Developments in the characterisation of complex rock slope deformation and failure using numerical modelling techniques. Engineering Geology, 83 (2006), pp. $217-235$.

Yan, M., Elmo, D. and Stead, D. (2007a) Characterisation of step-path failure mechanisms; A combined field basednumerical modelling study. 1st Canada - US Rock Mechanics Conference, May 27-June 1, 2007, Vancouver.

Yan, M., Stead, D. and Sturzenegger, M. (2007b) Step-path characterisation in rock slopes: An integrated digital imaging - numerical modelling approach. ISRM 2007, 11th Congress of the International Society of Rock Mechanics, July 9-13, 2007, Lisbon, Portugal. 